\title{
Crack formation, strain distribution and fracture surfaces around knots in thermally modified timber loaded in static bending
}

\author{
Joran van Blokland ${ }^{1} \cdot$ Anders Olsson $^{2} \cdot$ Jan Oscarsson $^{2} \cdot$ Geoffrey Daniel $^{3}$. \\ Stergios Adamopoulos ${ }^{1}$ (D)
}

Received: 27 January 2020 / Published online: 2 June 2020

(c) The Author(s) 2020

\begin{abstract}
The effect of thermal modification (TM) on the chemistry, anatomy and mechanical properties of wood is often investigated using small clear samples. Little is known on the effect of growth-related and processing defects, such as knots and checks, on the bending strength and stiffness of thermally modified timber (TMT). Nine boards of Norway spruce with different combinations of knot types were used to study the combined effects of checks and knots on the bending behaviour of TMT. Digital image correlation (DIC) measurements on board surfaces at sites of knots subjected to bending allowed to study strain distribution and localise cracks prior to and after $\mathrm{TM}$, and to monitor development of fracture (around knots) in TMT to failure. DIC confirmed that checking in knots was increased after TM compared to kiln-dried timber, specifically for intergrown knots and intergrown parts of encased knots. Effects appear local and do not affect board bending stiffness at these sites. Bending failure in TMT initiated mainly at knot interfaces or besides knots and fractures often propagated from checks. Scanning electron microscopy analyses of fracture surfaces confirmed this, and fractures were typically initiated around knots and at knot interfaces due to crack propagation along the grain in the longitudinal-radial plane (TL fracture) under mixed mode I and II loading, such that boards failed in simple tension like unmodified timber. Images of fracture surfaces at the ultrastructural level revealed details of the brittle behaviour of TM wood. This was especially apparent from the smooth appearance of transwall failure under mode I loading across the grain.
\end{abstract}

Stergios Adamopoulos

stergios.adamopoulos@1nu.se

1 Department of Forestry and Wood Technology, Linnaeus University, 35195 Växjö, Sweden

2 Department of Building Technology, Linnaeus University, 35195 Växjö, Sweden

3 Department of Forest Biomaterials and Technology/Wood Science, Swedish University of Agricultural Sciences, 75007 Uppsala, Sweden 


\section{Introduction}

Thermal modification (TM) is a process to improve the dimensional stability of wood against moisture content (MC) variations and biological resistance against decay (Rowell et al. 2009; Metsä-Kortelainen et al. 2011; Candelier et al. 2016). In the TM process, wood is heated for a specific time at low oxygen levels to avoid wood combustion. During TM, the cell wall material degrades to a certain extent through mainly loss and changes in hemicelluloses. At temperatures above $165^{\circ} \mathrm{C}$, cellulose also begins to degrade particularly in amorphous regions. Lignin, which is the most stable wood constituent at elevated temperatures, not only degrades but also forms new bonds. A thorough review on the effect of TM on changes in wood chemistry is given by Rowell et al. (2013). The chemical modification of cell wall polymers is thought responsible for changes in certain mechanical properties that are found after TM, specifically loss in strength and increased brittleness (Windeisen et al. 2009; Winandy and Rowell 2013; Gaff et al. 2019). In general, stiffness properties remain on a level similar to before modification (Kubojima et al. 2000; Majano-Majano et al. 2018; Gaff et al. 2019). Depending on the wood species and treatment conditions, the tensile and bending strength can reduce by as much as $40 \%$, while compression strength can increase by more than 10\% (Boonstra et al. 2007; Widmann et al. 2012; Hannouz et al. 2015). Work-to-maximum load, impact bending and fracture toughness are the mechanical properties that are most affected by TM (MacLean 1954; Kubojima et al. 2000; Hughes et al. 2015).

Wood anatomical defects caused by TM are reported to contribute to loss in strength (Boonstra et al. 2006a, b; Biziks et al. 2013; Altgen et al. 2017). However, this contribution compared to corresponding contributions due to changes in wood chemistry are difficult to establish. That would require strength tests on wood samples with and without these microscopic defects that have undergone similar changes in wood chemistry. For softwoods, microscopic defects in timber modified at industrial scale typically include cracks along rays, and damaged ray parenchyma and epithelial cells of rays and resin canal complexes, while latewood (LW) tracheids and pits remain intact (Boonstra et al. 2006a; Altgen et al. 2017). Less ambiguity between studies was found regarding observations of axially deformed earlywood (EW) tracheids or lengthwise cracks in radial cell walls of EW tracheids, and cell wall failure in tracheids perpendicular to the cell axis (i.e. transwall failure). An in situ measurement of cell features on the transverse plane during heat treatment by means of environmental scanning electron microscopy (ESEM) showed the development of cell wall cracks could not be ascribed to heat treatment, even though deformation of the wood structure under the influence of increasing temperature was substantial (Bernabei and Salvatici 2016). Therefore, it is reasonable to conclude that severe damages within or between cells in thermally modified wood (TMW) are caused by mechanisms related to the shrinkage anisotropy or differential shrinkage as reported by Boonstra et al. $(2006 a, b)$. Differential shrinkage can occur in timber because of the moisture gradient that develops in the cross section upon drying (Tsoumis 1991; Florisson 
et al. 2019). Drying stresses caused by these shrinkage differences lead to radial cracking upon drying (i.e. checks), especially at weak spots, such as rays or resin canal complexes in softwoods. Since drying progresses to approx. 0\% MC in the case of thermally modified timber (TMT), it is not surprising that typical conventional kiln-drying defects such as surface checks are more frequent and severe after TM (Altgen et al. 2012, 2017).

The effect of TM on changes in wood chemistry, anatomy and mechanical properties has been investigated mainly using small samples of clear wood (e.g. Kubojima et al. 2000; Boonstra et al. 2007; Hannouz et al. 2015). In timber, a combination of defects that originate from natural growth as well as processing will influence mechanical properties. For example, decrease in bending strength $\left(f_{\mathrm{m}}\right)$ of TMT of spruce and pine (ThermoWood ${ }^{\circledR}$; $\max .220{ }^{\circ} \mathrm{C} / 5 \mathrm{~h}$; process time 4 days) was as much as $50 \%$ compared to kiln-dried timber, while changes in bending stiffness were non-significant (Bengtsson et al. 2002). Similar results were obtained in an preceding investigation, and it was found that $f_{\mathrm{m}}$ predictions are possible for TMT, but relationships in terms of coefficients of determination $\left(R^{2}\right)$ between various predictor variables and $f_{\mathrm{m}}$ were weaker than for unmodified timber (van Blokland et al. 2020). Knots in timber are known to reduce bending strength considerably, but also affect stiffness (Kollmann 1968; Johansson 2003; Hu et al. 2016), and are thus taken into account in modern machine strength grading by fibre direction or X-ray scanning (Hanhijärvi and Ranta-Maunus 2008; Olsson et al. 2013; Olsson and Oscarsson 2017). Digital image correlation (DIC) has proven a valuable technique to show how strains measured on the surface of wood increase around knots in timber that is loaded (Oscarsson et al. 2012; Hu et al. 2015, 2016; Lukacevic et al. 2019). These strain concentrations are due to geometrical irregularities as well as changes in fibre direction close to the knot. Checks induced by drying stresses and MC changes, in contrast, have only limited influence on bending stiffness. Their influence on strength, however, has been less investigated, because this type of defect is difficult to detect, has a high level of randomness and often occurs in combination with knots (Mergny et al. 2016). A visual inspection with defined limits for the length of checks, splits and shakes is required in machine grading, whereas limitations on size of knots and clusters of knots are only specified in rules for visual strength grading (EN 1912 2012; EN 14081-1 2016). Checks and splits typically appear in normal wood that is seasoned, but their severity will be strongly affected by growth defects such as reaction wood and knots (Tsoumis 1991). Checks in knots are common in timber of Norway spruce that is kiln-dried (Folvik and Sandland 2003, 2005), but are not considered in visual strength grading rules (EN 1912 2012; EN 14081-1 2016). Checks in knots could have a large effect on bending stiffness as well as on strength (Kollmann 1968). Lukacevic et al. (2019) for example showed that simulation of a reduced local stiffness at sites of knots, used to take account the effect of checks in knots, gave good correlation with experimental results.

Common drying defects such as surface checks on the tangential surface in kiln-dried timber of spruce and pine became more frequent and severe after TM (ThermoWood $^{\circledR}$; $\max .212{ }^{\circ} \mathrm{C} / 3$ h; process time 3 days) (Altgen et al. 2012, 2017). Using the same TM process, van der Beek and Tiitta (2010) used in situ measurements of acoustic emissions on spruce timber with and without knots to monitor 
check formation during modification. Although test results were somewhat ambiguous, specimens with knots had higher count rates on average indicating a higher level of checking. Thus, it is reasonable to expect the severity of checks adjacent to and/or in knots increases during the TM process and thus could affect bending stiffness and strain distribution locally at sites of knots and development of failure in TMT. However, little is known concerning the effect of growth-related and processing defects, such as knots and checks on the bending behaviour of thermally modified timber (TMT). The purpose of the present study was to obtain a better understanding of the effects of TM on the bending strength and stiffness of Norway spruce timber. Therefore, the combined effect of checks and knots on the bending behaviour of TMT has been investigated on a selection of boards with typical knots. The objectives were: (1) visually assess the effect of TM on the level of checking around knots; (2) study the distribution of surface strain and bending stiffness and localise cracks with digital image correlation (DIC) measurements on the surface of boards at sites of knots loaded in bending prior to and after TM; and (3) monitor development of fracture (around knots) in TMT to failure with DIC and evaluate fracture surfaces in and around knots visually and by scanning electron microscopy (SEM) to reconstruct failure modes at such complex locations with high importance for the bending strength of TMT.

\section{Materials}

Nine boards were used for the study. The boards were sawn with a $2 \mathrm{X}-\log$ saw pattern from 9 logs of Norway spruce (Picea abies L. Karsten) that had a length $(L)$ of 3.6 to $4.8 \mathrm{~m}$ and were harvested north of Karlstad in central Sweden. These boards were sawn as part of a larger batch. A sample of that batch had been used in a previous study with the purpose of exploring possibilities for predicting the bending properties of TMT (van Blokland et al. 2020). After sawing, all boards were kilndried to approximately $12 \% \mathrm{MC}$ and then planed. The dry bulb temperature during drying was set to approx. $80{ }^{\circ} \mathrm{C}$ and the total drying time was approx. $100 \mathrm{~h}$. The sawing, drying and planing were carried out at Stora Enso's sawmill in Gruvön. One

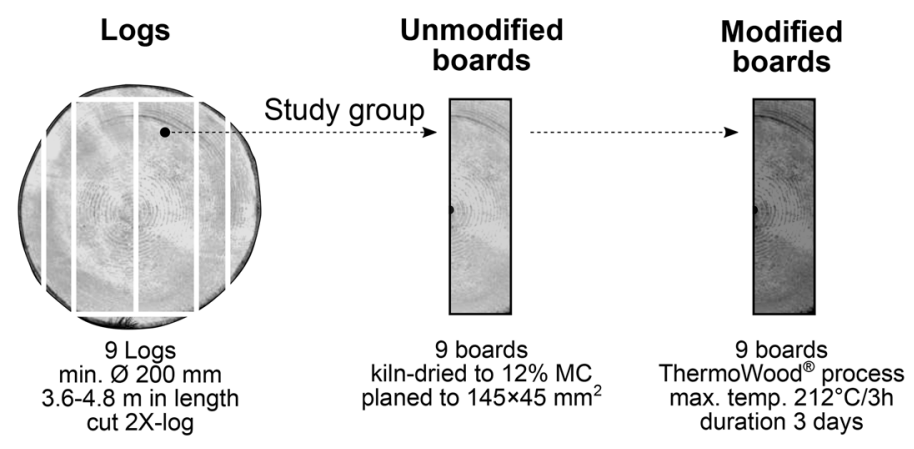

Fig. 1 Sampling of boards 
board from each of the 9 logs with a thickness $(t) 45 \mathrm{~mm}$ and width $(h) 145 \mathrm{~mm}$ was included for tests, and these boards are referred to as unmodified boards (Fig. 1). The boards were stored in the laboratory hall of Linnaeus University, Sweden, at room temperature conditions (approx. $20^{\circ} \mathrm{C}$ and $60 \% \mathrm{RH}$ ) prior to testing.

Boards were selected with different combinations of knot types representative of the larger batch and located at, or close to the assumed weakest section along the board's length (i.e. less than $\pm 500 \mathrm{~mm}$ ). Areas with 'normal'-sized knots, which are allowed in the second lowest visual strength grading class T1 according to INSTA 142 (2010) were included. One board with a large area of clear wood was also selected. Influence of other features was excluded as much as possible. Figure $2 \mathrm{a}-\mathrm{h}$ shows the selected area $A$ on a section of each of the 8 unmodified boards in exploded $2 \mathrm{D}$ view including all four sides. The boards are labelled by letters, i.e. board $a$ to $h$. The centre point of knot clusters measured from the root end (dash-dotted line), knot types and size in $\mathrm{mm}$ are given for each board in Fig. 2. The selected area of the $9^{\text {th }}$ board (excluded from Fig. 2) was defect free, and this board is referred to as board $i$. Three nails in each board define a local-coordinate system $x y z$, which is also shown in Fig. 2 on each board's face where surface strains were measured. Each board shown in Fig. 2 included a specific type of knot that is highlighted with an asterisk symbol. In general, these boards have splay knots since they were sawn 2X-log, and thus visual grading class T3 (C30) is not allowed (INSTA 142 2010).

Thermal modification of the 9 boards was carried out according to the ThermoWood $^{\circledR}$ process in an industrial batch to meet class Thermo-D (Fig. 1). This process has a peak temperature of $212{ }^{\circ} \mathrm{C}$ that is maintained for $3 \mathrm{~h}$ with a total treatment time of 3 days (International ThermoWood Association 2003). TM was carried out by Stora Enso at their plant in Launkalne in Latvia. After TM, unmodified boards $a-i$ are referred to as thermally modified (TM) or simply modified boards.

\section{Methods}

\section{Experimental}

The type and size of knots in the selected areas of the unmodified boards in Fig. 2 were determined according to INSTA 142 (2010). The effect of TM on the number and size of checks in and around various types of knots, i.e. edge, face, arris and splay knots both intergrown as well as encased, was evaluated by comparing macroscopic images of the same knot before and after TM. Board mass, dimensions and first axial resonance frequency $\left(f_{\mathrm{a}, 1}\right)$ were determined for boards before and after TM. These non-destructive tests were used to calculate the board density $(\rho)$ and axial dynamic modulus of elasticity $\left(E_{\mathrm{a}, 1}\right)$. A description of the methods are found in Perstorper (1994), and details of how they were implemented in this study were described by van Blokland et al. (2020).

Prior to TM, the 9 unmodified boards were loaded non-destructively up to a load $(F)$ of $3.5 \mathrm{kN}$ in edgewise bending in the testing machine ALWETRON TCT 100 (Lorentzen \& Wettre AB, Stockholm, Sweden) following EN 408 (2012). In spruce 

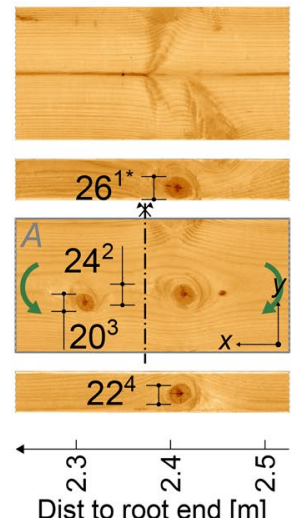

Dist to root end [m]

$\left.{ }^{1 *}, 4\right)$ Edge knot

${ }^{2,3)}$ Face knot intergrown

a

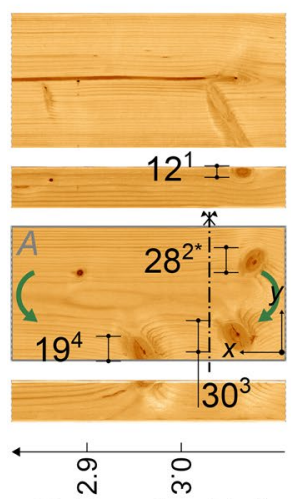

Dist to root end [m]

${ }^{1)}$ Splay knot ${ }^{2,3}$ Face knot

${ }^{4)}$ Arris knot intergrown

e
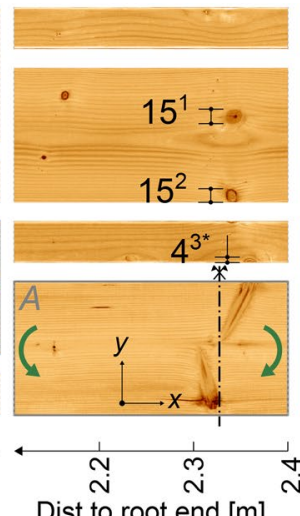

Dist to root end [m]

1) Face knot

${ }^{2)}$ Arris knot

${ }^{3^{*}}$ Splay knot "encased

b

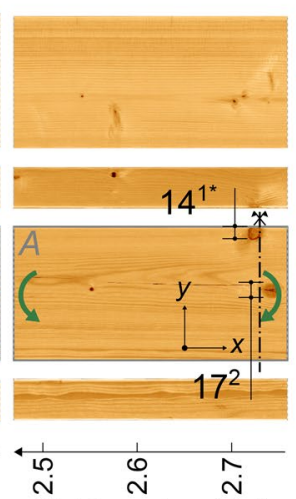

Dist to root end [m]

$\left.{ }^{1 *}\right)$ Arris knot

${ }^{2)}$ Face knot

*encased

f

of 12

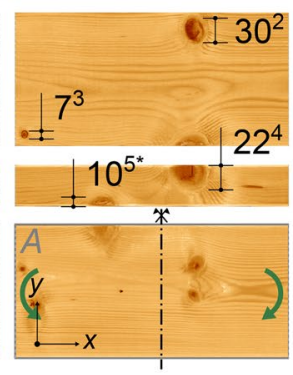

$\infty$

Dist to root end [m]

Dist to root end [m]

${ }^{1)}$ Face knot

${ }^{2 *}$ Edge knot

*encased

C

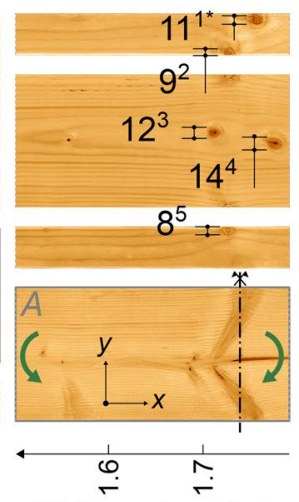

Dist to root end [m]

$\left.{ }^{1 *}\right)$ Splay knot

2,5)Arris knot

3,4) Face knot

"intergrown

g
${ }^{1)}$ Edge knot

2,3) Face knot

${ }^{\left.4,5^{*}\right)}$ Arris knot

*intergrown

d

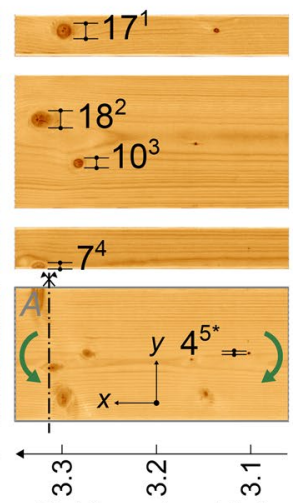

Dist to root end [m]

${ }^{1)}$ Edge knot

2,3,5*) Face knot

${ }^{4)}$ Arris knot

"encased (<7 mm)

h

Fig. 2 Selected area $A$ on each unmodified board surface at given distance to root end (m) $\mathbf{a}-\mathbf{h}$ including knot type and size $(\mathrm{mm})$, position of the centre of the knot cluster, and local-coordinate system xyz. Note green arrows indicate internal bending moment upon testing

clear wood, this load should correspond to a longitudinal strain of approx. $0.1 \%$ and stress of approx. $10 \mathrm{MPa}$ at beam edge (Dinwoodie 2000). Global (w) and local (v) deflection and force $(F)$ were recorded in a catman ${ }^{\circledR}$ data acquisition system (DAQ) (HBM, Darmstadt, Germany). In this set up (Fig. 3a), the weakest section including 
LVDT mounted on steel

Potentiometer to measure global frame to measure local deflection $w$ over length $L$ deflection $v$ over length I
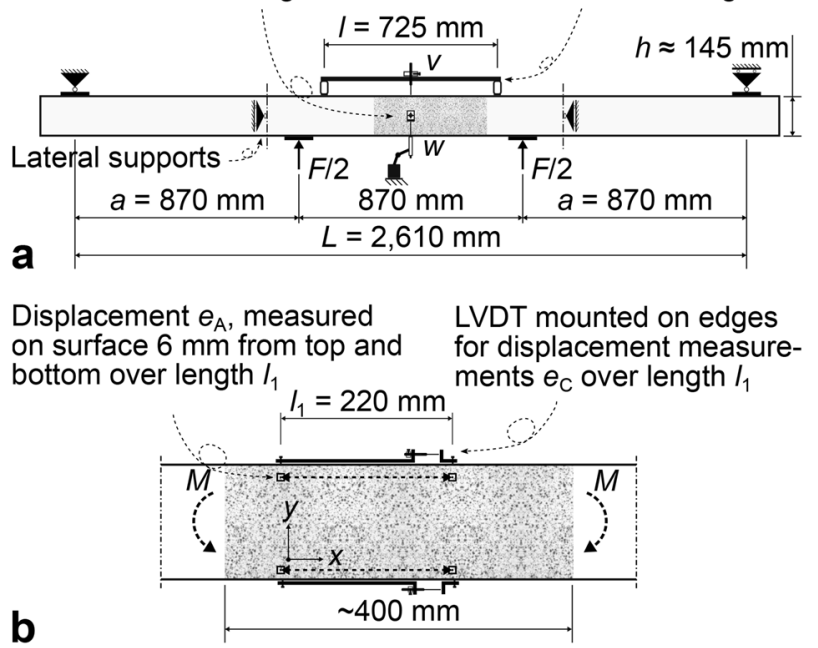

Fig. 3 Set up for 4-point static bending test. a Overview based on EN 408 (2012), and b speckle pattern on the board's surface at the selected area $A$ for DIC measurement. Note that the illustrated moment $M$ is an internal bending moment

the selected area $A$ as shown in Fig. 2 was positioned between the load points. The tension side of each board was selected randomly and green arrows in Fig. 2 indicate the internal bending moment $(M)$. The speed of loading was operated manually applying a constant load rate over time. The moisture content (MC) of the unmodified boards was obtained using a pin-style moisture meter (RDM-2S, Delmhorst Instrument Co., Towaco, USA). Board cross-sectional dimensions $(t \times h)$ were taken in the weakest section at the time of testing. After unloading, each board was loaded again using the same set up as described above, but this time relative displacement on the surface as well as of the outer fibres $\left(e_{\mathrm{C}}\right)$ was recorded by the use of a noncontact optical deformation measurement system (Aramis adjustable, GOM GmbH, Germany) and two linear variable differential transformers (LVDTs), respectively. Details are shown in Fig. 3b. Both test runs were repeated after thermal treatment of the 9 TM boards; however, during the last (i.e. 4th) run, boards were bent to failure and maximum load was recorded $\left(F_{\max }\right)$. MC of the modified boards was determined directly after testing by using the oven-dry method (EN 13183-1 2002).

Prior to testing, a black on white speckle pattern was applied over the measurement areas, i.e. the face of each board at position of the selected area $A$ with a length of roughly $400 \mathrm{~mm}$ (Figs. 2, 3). The nails used to define a board's local coordinate system were marked as black dots. Each camera had a 24-mm lens with a full frame resolution of $4096 \times 3072$ pixels. The measuring area used for the 9 unmodified boards was $670 \times 545 \times 545 \mathrm{~mm}^{3}$ (length $\times$ width $\times$ depth). After modification, this measurement area was increased to $890 \times 725 \times 725 \mathrm{~mm}^{3}$ to capture the whole area on the board's surface in-between the load points, such that initiation and 
development of failure occurred in the field of vision. Images during loading were taken at 2 and $1 \mathrm{~Hz}$ for unmodified and TM boards, respectively. Input signal $F$ from catman ${ }^{\circledR}$ was loaded into ARAMISTM, such that each image corresponded to a certain load level.

For SEM, 11 small samples with a maximum size of $1 \mathrm{~cm}^{3}$ were taken from fracture surfaces of TM boards after failure (primarily in tension) by cutting without disturbing the fracture zone. In detail, initial samples were isolated by cutting the timber with a razor blade behind the fracture surface. Final samples for SEM analyses were prepared under a stereomicroscope using forceps and fresh razor blades. It was thus ensured that the surface areas of interest were not touched in the process, and mechanical damage of the fine structures was avoided. From these samples, 6 were clear wood samples to study fracture across the grain (boards $a, b, g$ and $h$ ) and along the grain (boards $d$ and $g$ ). The other 5 samples were included to observe fractures in (boards $a, c$ and $d$ ) and around (boards $a, c, d$ and $g$ ) knots including the knot interface. Samples were mounted on aluminium stubs with the help of adhesive carbon pads, and then sputter-coated with 20-30 $\mu \mathrm{m}$ gold (Emitech K550X, Quorum Technologies, West Sussex, UK). Samples were analysed with an environmental scanning electron microscope (XL30 ESEM, Philips/FEI) under vacuum using a $10 \mathrm{kV}$ electron beam resulting in magnifications in the range of 16-6500 times. Besides analysing samples with SEM, the fracture surfaces in and around knots were also evaluated visually.

\section{Calculation of surface strain}

Determination of strain and displacement fields was based on digital image correlation (DIC) using the ARAMISTM software (GOM Correlate, GOM Software 2018). By dividing the measurement area in small square sections, called facets, grey scale values of each pixel in a facet are used to recognise and track facets upon deformation. The centre of each facet, the facet nodal point, was used to construct a triangular mesh. The base length of one hexagon within this mesh (a hexagon build-up of 6 triangles) is used to calculate strain. The facet size was set to $15 \times 15$ pixels with a point distance of 11 pixels for unmodified boards and 8 pixels for modified boards. The difference in point distance was chosen such that the point density between the measurements before and after TM was similar. This was on average 30 facet nodal points per $\mathrm{cm}^{2}$, which corresponds to a spatial resolution between each nodal point of about $1.6 \mathrm{~mm}$ in $y$-direction and $1.8 \mathrm{~mm}$ in $x$-direction. Calculations were done using the software's standard calculation and the so-called strain tensor neighbourhood was set to 2 (i.e. 'high resolution') or 4 (i.e. 'low resolution'). Strain was therefore calculated over a reference length of 4-5 $\mathrm{mm}$ or 8-9 $\mathrm{mm}$, respectively. The measured area was limited to about $5 \mathrm{~mm}$ inward from each board's edge to avoid measurement errors at the edges. Subsequently, the longitudinal $\left(\varepsilon_{x}\right)$, lateral $\left(\varepsilon_{y}\right)$ and shear $\left(\varepsilon_{x y}\right)$ strains on the board's surface could be calculated over the measured areas by the ARAMISTM software. In this way, each image corresponded to a certain strain stage. Comparisons of strain measured on unmodified and modified boards were done at similar bending 
stress levels of 8-9 MPa on the outer fibres (i.e. $F$ of approx. $3 \mathrm{kN}$ ). Displacement close to the outer fibres (i.e. about $6 \mathrm{~mm}$ inward from the board's top and bottom edges) determined using strain gauges and denoted $e_{\mathrm{A}}$ was measured over a length of $220 \mathrm{~mm}$ as shown in Fig. 3b. Because of shrinkage after modification, which is particularly noticeable over the width $(h)$ of the board, the position of strain gauges on measurement area $A$ were adjusted accordingly.

A low resolution or increased strain reference length is required to minimise the noise and make it small compared to the strain measured. A lower resolution allows a lower level of noise, because of the set accuracy with which the DIC system can measure displacements (Hu et al. 2018). Strain calculated over 4-5 mm corresponded to a noise level in strain of approx. $\pm 0.2 \%$, and to approx. $\pm 0.1 \%$ when calculated over $8-9 \mathrm{~mm}$. In contrast, high resolution is required to determine location of cracks as accurately as possible. Axial strains in wood of Norway spruce that exceeded $\pm 0.5 \%$ were assumed to be associated with the presence of a check or crack, which opened or closed (Sjödin et al. 2006; Oscarsson et al. 2012). Strains determined over a crack are not actual material strains, but measures of crack opening, and levels of these 'apparent strains' also depend on the resolution. This means that for similar crack widening, levels of apparent strain double when the reference length is halved. The 'high-resolution' setting was used to detect checks prior to and after modification (at $F \approx 3 \mathrm{kN}$ ), and to follow crack propagation in TM boards upon loading. For both the unmodified and modified boards, the minimum $\left(\varepsilon_{x, \text { min }}\right)$ and maximum $\left(\varepsilon_{x, \text { max }}\right)$ longitudinal (apparent) strains were determined over the surface area $A$ (Fig. 2). The 'low-resolution' setting was used to evaluate strain distribution prior to and after modification at sites of knots located in area $A$. These settings allowed measurements of strain above $0.1 \%$, but below $0.5 \%$, with sufficient accuracy. Here, a strain mask excluded measures of apparent strain.

\section{Evaluation of board properties}

Bending stress was calculated assuming a linear elastic stress distribution over the rectangular (homogenous) cross section as

$$
\sigma_{\mathrm{m}}=\frac{M}{W}=\frac{a \frac{1}{2} F}{\frac{1}{6} t h^{2}},
$$

where $M$ is the bending moment $(\mathrm{N} \mathrm{mm})$ calculated from total force $F$ and the distance $a$ between the support and load point, $W$ the elastic section modulus $\left(\mathrm{mm}^{3}\right)$, and $t$ and $h$ are the cross-sectional dimensions (see also Fig. 3a). Bending stress was calculated for each board and test run. Bending strength $\left(f_{\mathrm{m}}\right)$ of modified boards was calculated from $F_{\text {max }}$ of destructive tests (4th test run). Local $\left(E_{\mathrm{m}, 1}\right)$ and global $\left(E_{\mathrm{m}, \mathrm{g}}\right)$ bending MOE were calculated from $v$ and $w$, respectively, according to $\mathrm{EN}$ 408 (2012). Strain at the top $\left(\varepsilon_{\text {top }}\right)$ and bottom sides $\left(\varepsilon_{\text {bot }}\right)$ of each board was calculated from $e_{\mathrm{C}}$ and $e_{\mathrm{A}}$ as the change in length over the original length, and used to 
determine the bending MOE over a board length of $220 \mathrm{~mm}$ at interval $x[-10 ; 210]$ (see $x y z$ in Fig. 2), which often included a cluster of knots, as follows:

$$
E_{\mathrm{m}}=\frac{2 \cdot\left(\sigma_{\mathrm{m}} / h \cdot z\right)}{\varepsilon_{\mathrm{top}}+\left|\varepsilon_{\text {bot }}\right|},
$$

where $z$ is the internal lever arm calculated as the board width $(h)$ minus twice the distance from the boards edge to the location of the strain measurement $e_{\mathrm{A}}$. For $e_{\mathrm{C}}$, $z$ equals $h$. If $E_{\mathrm{m}}$ in Eq. 2 was calculated from strain field measurements, i.e. $e_{\mathrm{A}}$, it is referred to as $E_{\mathrm{m}, \mathrm{A}}$, and if from LVDTs, i.e. $e_{\mathrm{C}}$, as $E_{\mathrm{m}, \mathrm{C}}$. Linear regression was used to obtain $\varepsilon_{\text {top }}$ and $\varepsilon_{\text {bot }}$ at $\sigma_{\mathrm{m}}$ of a bending stress-outer fibre strain $\left(\sigma_{\mathrm{m}}-\varepsilon\right)$ curve. All calculations and statistics were performed in Matlab ${ }^{\circledR}$. Differences between properties measured on unmodified and modified boards were made using $F$ tests, and independent or paired $t$ tests.

\section{Results and discussion}

\section{Board properties}

Table 1 shows mean, standard deviation (std) and coefficient of variation $(\mathrm{CoV})$ values of board properties determined before, and after TM. The mean density $(\rho)$ was about 480 and $450 \mathrm{kgm}^{-3}$ at given MC for unmodified and modified boards, respectively, and was reduced by $6 \%$ due to TM. This reduction included the difference in MC, which was on average $11.2 \%$ for unmodified and $4.4 \%$ for modified boards at the time of testing, and was significantly lower after modification. Mean values of bending stiffness for both sample sets ranged between 10.0 and $13.4 \mathrm{GPa}$, and varied somewhat depending on how and where deformation was measured (Table 1). The

Table 1 Mean values \pm standard deviation $(\mathrm{CoV})$ for different properties of unmodified and modified boards

\begin{tabular}{llccc}
\hline Property & Unmodified & Modified & $F$ test $^{\mathrm{a}}$ & ${\text { Paired } t \text { test }^{\mathrm{b}}}^{\mathrm{a}}$ \\
\hline $\mathrm{MC}(\%)$ & $11.2 \pm 1.2(10 \%)$ & $4.4 \pm 0.5(12 \%)$ & $0.193^{0.032}$ & $-16.9^{<0.001}$ \\
$\rho\left(\mathrm{kg} \mathrm{m}^{-3}\right)$ & $481 \pm 58(12 \%)$ & $452 \pm 50(11 \%)$ & $0.719^{0.651}$ & $-3.26^{0.012}$ \\
$E_{\mathrm{a}, 1}(\mathrm{MPa})$ & $13,701 \pm 1860(14 \%)$ & $13,433 \pm 2019(15 \%)$ & $1.18^{0.821}$ & $-2.65^{0.029}$ \\
Bending stiffness & & & & \\
$E_{\mathrm{m}, \mathrm{g}}(\mathrm{MPa})$ & $12,888 \pm 1705(13 \%)$ & $12,518 \pm 1894(15 \%)$ & $1.23^{0.774}$ & $-3.79^{0.005}$ \\
$E_{\mathrm{m}, \mathrm{l}}(\mathrm{MPa})$ & $13,418 \pm 2222(17 \%)$ & $13,237 \pm 2191(17 \%)$ & $0.972^{0.969}$ & $-1.54^{0.162}$ \\
$E_{\mathrm{m}, \mathrm{C}}(\mathrm{MPa})$ & $10,233 \pm 2424(24 \%)$ & $10,041 \pm 2577(26 \%)$ & $0.884^{0.867}$ & $1.41^{0.196}$ \\
$E_{\mathrm{m}, \mathrm{A}}(\mathrm{MPa})$ & $12,548 \pm 3132(25 \%)$ & $12,038 \pm 3344(28 \%)$ & $0.877^{0.857}$ & $3.28^{0.011}$ \\
Bending strength & & & & N.A. \\
$f_{\mathrm{m}}(\mathrm{MPa})$ & N.A. & $27.2 \pm 9.9(36 \%)$ & N.A. \\
\hline
\end{tabular}

${ }^{\mathrm{a}} F$-value ${ }^{p \text { value }}$

${ }^{\mathrm{b}} t$-value ${ }^{p \text { value }}$ 
difference between unmodified and modified boards for $E_{\mathrm{m}, \mathrm{g}}$ and $E_{\mathrm{m}, \mathrm{A}}$ was statistically significant, but less than $4 \%$. These differences appeared non-significant for $E_{\mathrm{m}, 1}$ and $E_{\mathrm{m}, \mathrm{C}}$. Thus, based on these properties, it can be concluded that the local bending stiffness at sites of knots was similar for unmodified and modified boards and therefore unaffected by TM, as previously confirmed for mean values of MOE from static bending and axial vibration tests (Bengtsson et al. 2002; Widmann et al. 2012; van Blokland et al. 2020). Interestingly, bending stiffness calculated from $\sigma-\varepsilon$ curves was $387 \mathrm{MPa}(5 \%)$ and $891 \mathrm{MPa}(9 \%)$ lower after TM for board $e$, and $872 \mathrm{MPa}(13 \%)$ and $1017 \mathrm{MPa}(11 \%)$ lower after TM for board $a$, for $E_{\mathrm{m}, \mathrm{C}}$ and $E_{\mathrm{m}, \mathrm{A}}$, respectively. Although these values were the largest reductions found, there was no clear relationship between the reduction in bending stiffness after TM and the size of knot clusters. For both sample sets, average values of local bending $\operatorname{MOE}\left(E_{\mathrm{m}, 1}\right)$ were about $5 \%$ higher compared to global bending $\operatorname{MOE}\left(E_{\mathrm{m}, \mathrm{g}}\right)$. For all unmodified and modified board pairs, $E_{\mathrm{m}, \mathrm{C}}$ was lower than $E_{\mathrm{m}, \mathrm{A}}$, and the difference in mean was as much as $20 \%$, but not systematic and due to the spread in data not significant (independent $t$ test; $p \geq 0.1$ ). The bending strength from tests $\left(f_{\mathrm{m}}\right)$ of TM boards was $27 \pm 10 \mathrm{MPa}$ (mean \pm std) (Table 1). Except for changes in MC, the variation of properties in Table 1 was statistically equivalent between the two sample sets. Overall, results are consistent with earlier findings regarding the level and variation of board properties of Norway spruce timber (Olsson and Oscarsson 2017; van Blokland et al. 2020), and the effect of TM on these properties (Bengtsson et al. 2002; Widmann et al. 2012; van Blokland et al. 2020).

\section{Checks in knots}

An overview of different types of knots and associated checks visible on the surface of unmodified and modified boards is shown in Fig. 4. The figure includes face, edge, arris and splay knots, which were either intergrown (left side) or encased (right side). Arrows indicate the tip of dominant checks and the direction in which they have developed. The knots in Fig. 4 are typical for boards that are sawn $2 \mathrm{X}$-log and correspond to knots in boards $a-h$ highlighted with an asterisk in Fig. 2, but were located at a different position along the board's length. The number and size of (surface) checks in knots were increased after TM, especially for intergrown knots and intergrown parts of encased knots (see encased edge and splay knots). This is consistent with earlier studies on the development of checks in TMT (van der Beek and Tiitta 2010; Altgen et al. 2012, 2017). Folvik and Sandland (2003, 2005) emphasised earlier that Norway spruce is a species that is particularly prone to check formation in knots and found similar patterns of checks in intergrown knots in kiln-dried Norway spruce. In those studies, pronounced checking was found over the full width of the knot perpendicular to the board's long axis, and was explained by a difference between radial shrinkage of the knot wood (i.e. 3-8\% measured from green to $2 \% \mathrm{MC}$ ) and longitudinal shrinkage of the stem wood (i.e. less than $1 \%$ ) (Boutelje 1966; Paulínyová and Čunderlík 2006; Saranpää 2008). Radial checks in encased knots (Fig. 4) as well as radial checks in intergrown knots not explained by the stem-knot wood shrinkage difference, were associated with the tangential 


\section{Face}
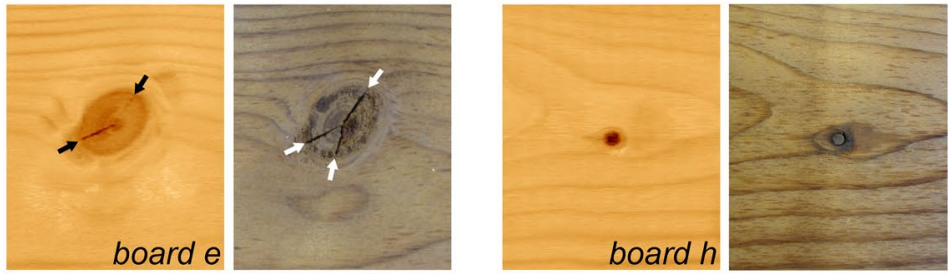

\section{Edge}
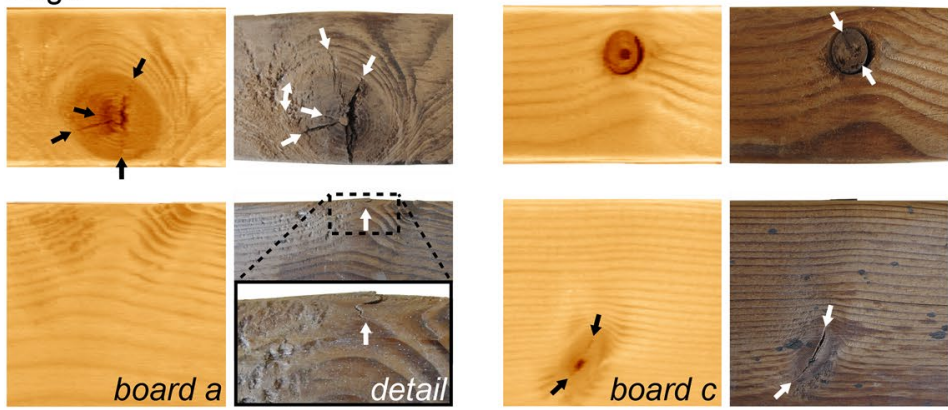

Arris
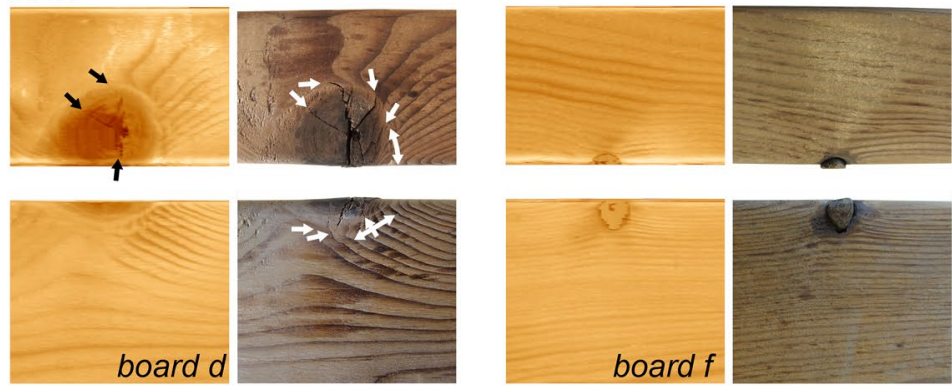

\section{Splay}
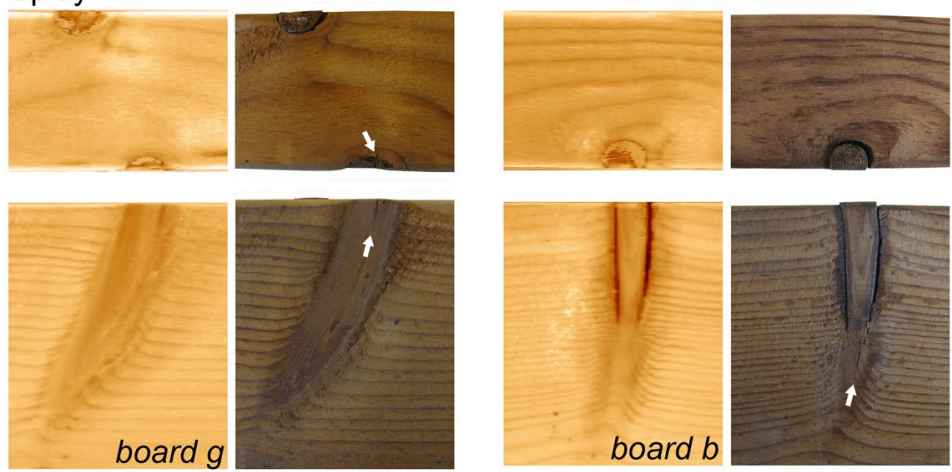

Intergrown

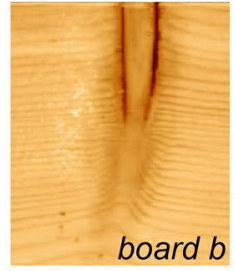

Encased
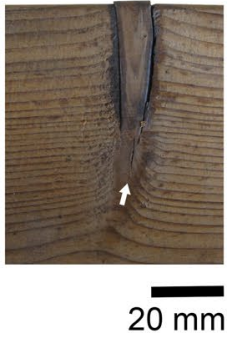

Fig. 4 Surface checks in various types of knots for unmodified (left) and modified (right) boards. Note that the boards' root end is to the left and arrows indicate checks 
shrinkage of knot wood (Folvik and Sandland 2005), that ranged between 4-9\% for Norway spruce wood measured from green to $2 \%$ MC (Boutelje 1966).

After TM, knots protruded a couple of mm (Fig. 4), which was particularly obvious for encased knots. Radial shrinkage of Norway spruce stem wood has been reported as approx. 4\% (Paulínyová and Čunderlík 2006; Saranpää 2008), whereas longitudinal shrinkage of wood taken from the upper and lower side of knots was found as approx. 0.5 and 6\%, respectively, measured from green to $2 \% \mathrm{MC}$ (Boutelje 1966). Not surprisingly, even wood of intergrown knots protruded after TM (Fig. 4), especially on the upper side of knots. This was not observed for kiln-dried boards, because the boards were planed after kiln drying. In addition to checks developed radially in knots, checks were observed along the knot-stem wood border of large intergrown knots (indicated with double arrow symbol in Fig. 4), which are likely caused by a combination of differences in shrinkage described above. Besides the differences in shrinkage of knot and stem wood, the lower tensile strength perpendicular to grain and reduction in mode I fracture toughness $\left(K_{\mathrm{c}}\right)$ and fracture energy $\left(G_{\mathrm{f}}\right)$ found for TM wood compared to unmodified wood may contribute to the increased formation of checks (Reiterer and Sinn 2002; Boonstra et al. 2007; Widmann et al. 2012; Murata et al. 2013; Pleschberger et al. 2014; Tukiainen and Hughes 2016).

\section{Strain fields}

In this section, the axial strains $\left(\varepsilon_{x}\right)[\%]$ measured on the surface of unmodified and modified boards are compared. Colour plots of strain at 'high resolution' over the selected area $A$ including diagrams at specific sections are shown in Fig. 5, values of $\varepsilon_{x, \text { min }}$ and $\varepsilon_{x, \text { max }}$ in Table 2, and colour plots of strain at 'low resolution' of knots in the tensile zone of area $A$ in Fig. 6.

\section{Apparent strain and checks}

A change in the distribution of apparent strain between unmodified and modified state was observed for boards $a$ and $e$ (board $a$ is displayed in Fig. 5a as example). Boards $a$ and $e$ were characterised by relatively large intergrown knots (Fig. 2). Figure 5a shows that there was a shift in the location of $\varepsilon_{x \text {, max }}$, and high values of apparent strain ran further over the boards' height after TM (see diagram and colour plot at $y=120 \mathrm{~mm}$ ). Similar observations were made for boards $b$ and $g$, both characterised by a double splay knot (Fig. 2) (board $b$ is used in Fig. 5b as example). For example, Fig. 5b shows values of axial apparent strain at the centre of the knot over the living (intergrown) part of the encased knots after TM, which were not present prior to modification. For boards $c, d$ and $h$, these differences in location of (apparent) strains after TM were less pronounced. Boards $c, d$ and $h$ had smaller knots (arris knots) or no knots at or close to the board edges (Fig. 2), whereas larger knots were not captured by the cameras in these boards. Figure $5 \mathrm{c}$ shows $\varepsilon_{x}$ over board $h$ as example. Board $i$ with a large area of clear wood showed that average strains in the tensile and compressive zone were about $\pm 0.1 \%$, while 


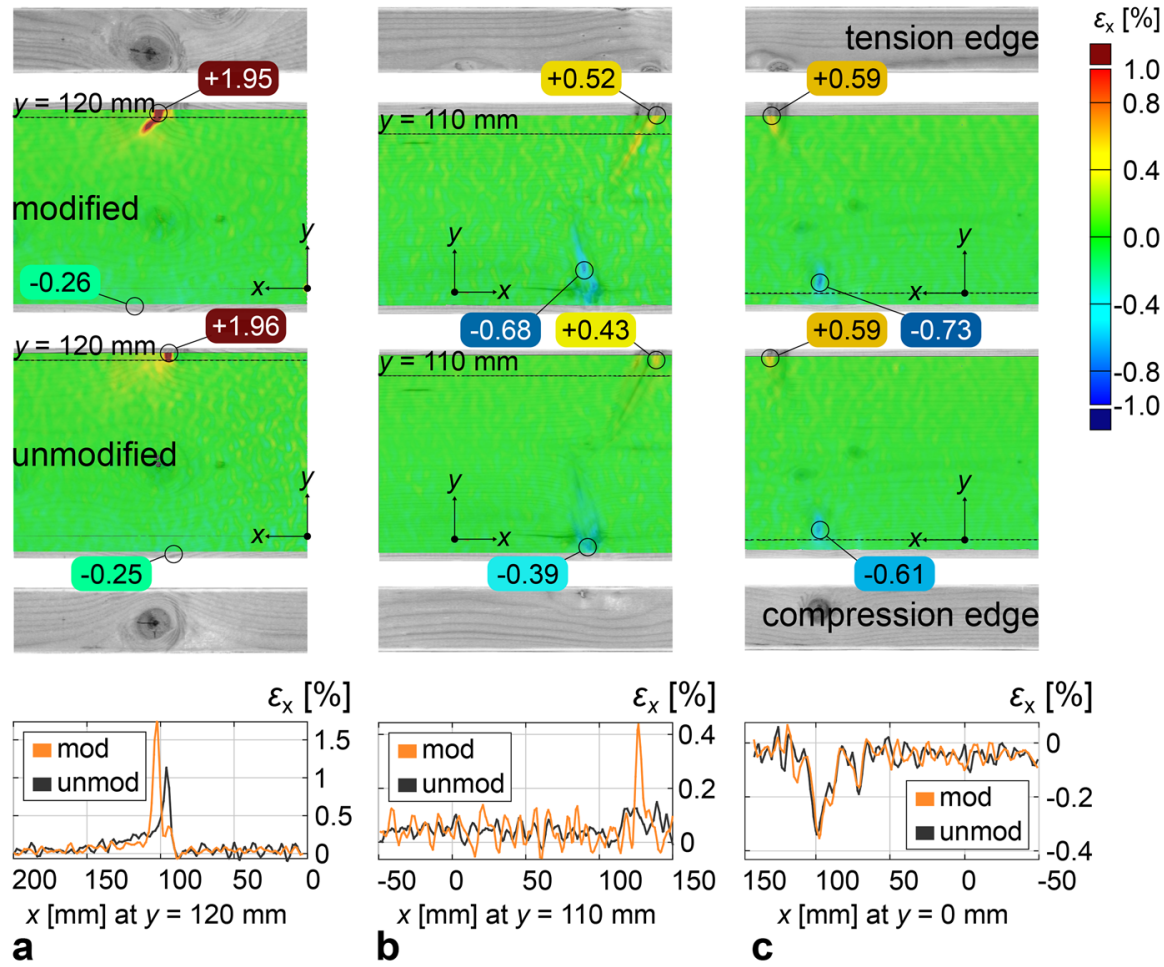

Fig. 5 Colour plots of axial strain $\left(\varepsilon_{x}\right)(\%)$ at 'high resolution' over the surface of unmodified (bottom) and modified (top) boards at $\sigma_{\mathrm{m}}$ of 8-9 $\mathrm{MPa}$ including minimum $\left(\varepsilon_{x, \min }\right)$ and maximum $\left(\varepsilon_{x, \max }\right)$ strain (values in boxes), and a diagram of $\varepsilon_{x}$ over the given $y$-sections: a board $a$, b board $b$ and $\mathbf{c}$ board $h$

minimum and maximum strains ranged between -0.2 and $0.2 \%$, both for unmodified and modified boards at the given load level. These levels of minimum and maximum strain in clear wood are consistent with previous studies, where wood of Norway spruce was loaded with about $10 \mathrm{MPa}$ in tension (Oscarsson et al. 2012) or bending (Hu et al. 2016).

The location of apparent strain corresponded well to the presence of checks in knots both for unmodified and modified boards (Figs. 4, 5). This is particularly true for checks that were oriented along the transverse board direction in knots located in the outer zones of the board. The increase in checks in face knots after TM was less obvious when looking at the apparent strain in Fig. 5, since these knots were located closer to the boards' neutral axis, where bending stress was considerably lower.

Table 2 presents maximum $\left(\varepsilon_{x, \max }\right)$ and minimum $\left(\varepsilon_{x, \max }\right)$ axial strain measured on the surface of boards $a-i$, and includes the percentage difference in axial strain between board pairs. Values of $\varepsilon_{x, \max }$ were located in the tensile zone of the selected areas ( $A$ in Fig. 2) close to, or in, a knot for all boards except for board $i$ with no knots, and mean values were $0.71 \%$ for unmodified and $0.79 \%$ 
Table 2 Minimum and maximum axial (apparent) strain (\%) measured on surfaces of unmodified and modified boards $a-i$ including pairwise difference (\%), and mean and standard deviation values (mean \pm std)

\begin{tabular}{|c|c|c|c|c|c|c|}
\hline \multirow[t]{2}{*}{ Board } & \multicolumn{3}{|l|}{$\varepsilon_{x, \max }$} & \multicolumn{3}{|l|}{$\varepsilon_{x, \text { min }}$} \\
\hline & $\begin{array}{l}\text { Unmodified } \\
(\%)\end{array}$ & Modified (\%) & $\begin{array}{l}\text { Difference } \\
(\%)\end{array}$ & $\begin{array}{l}\text { Unmodified } \\
(\%)\end{array}$ & Modified (\%) & Difference $(\%)$ \\
\hline$a$ & 1.96 & 1.95 & -1 & -0.25 & -0.26 & 4 \\
\hline$b$ & 0.43 & 0.52 & 22 & -0.39 & -0.68 & 71 \\
\hline$c$ & 0.59 & 0.63 & 8 & -0.23 & -0.23 & 3 \\
\hline$d$ & 1.01 & 1.57 & 56 & -0.24 & -0.4 & 69 \\
\hline$e$ & 0.38 & 0.28 & -27 & -1.74 & -2.1 & 20 \\
\hline$f$ & 0.94 & 0.65 & -31 & -0.29 & -0.45 & 55 \\
\hline$g$ & 0.33 & 0.74 & 125 & -0.47 & -1.42 & 200 \\
\hline$h$ & 0.59 & 0.59 & 0 & -0.61 & -0.73 & 18 \\
\hline$i$ & 0.19 & 0.22 & 14 & -0.23 & -0.24 & 7 \\
\hline Mean \pm std & $0.71 \pm 0.51$ & $0.79 \pm 0.55$ & $18^{*} \pm 45$ & $-0.49 \pm 0.46$ & $-0.72 \pm 0.60$ & $50^{* *} \pm 59$ \\
\hline
\end{tabular}

*No significant difference: $t$ test; $h_{0}: \mu=0$ versus $h_{1}: \mu>0 ; t=1.31$ and $p=0.23$

**Significant difference: $t$ test; $h_{0}: \mu=0$ versus $h_{1}: \mu>0 ; t=2.72$ and $p=0.03$

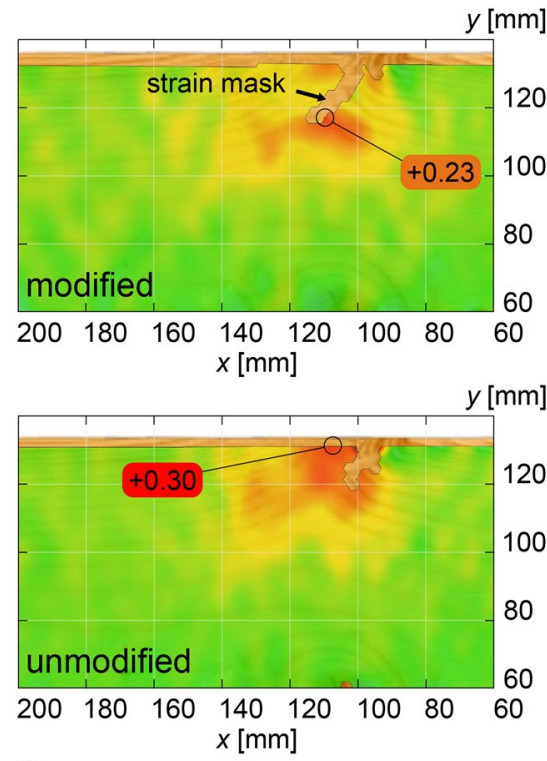

a

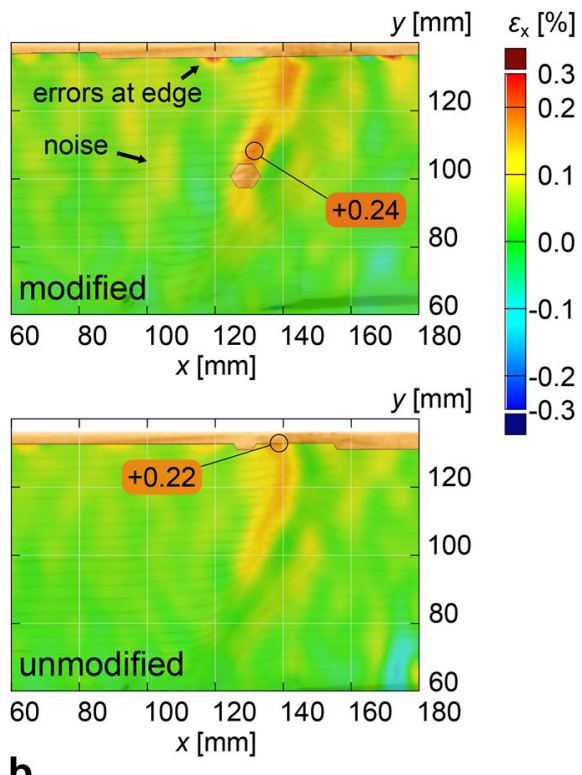

b

Fig. 6 Colour plots of axial strain $\left(\varepsilon_{x}\right)(\%)$ at 'low resolution' over the surface of unmodified (bottom) and modified (top) boards at $\sigma_{\mathrm{m}}$ of 8-9 MPa including maximum strain (values in boxes): a board $a$ at edge knot, b board $g$ at superficial splay knot 
for modified boards. Values of $\varepsilon_{x \text {,min }}$ were located in the compressive zone of the analysed areas ( $A$ in Fig. 2 ) close to, or in a knot for every board except for boards $c, f$ and $i$ with no knots in this zone, and mean values were $-0.49 \%$ for unmodified and $-0.72 \%$ for modified boards. The location of $\varepsilon_{x, \max }$ and $\varepsilon_{x, \min }$ was clearly related to the presence of knots both for unmodified and modified boards, as was shown earlier for unmodified spruce (Oscarsson et al. 2012; Hu et al. 2015, 2016; Lukacevic et al. 2019). No significant increase in the mean value of the pairwise difference of $\varepsilon_{x \text {,max }}$ was found, i.e. measures of apparent tensile strain were unchanged (Table 2). Checks in knots (gaps) loaded in tension, therefore, open up similarly in unmodified and modified boards. In contrast, values of $\varepsilon_{x \text {,min }}$ were larger for every board after TM and on average $\varepsilon_{x \text {,min }}$ was significantly increased by as much as $50 \%$ (Table 2). In compression, checks can close further after TM since these are larger/wider (Fig. 4), such that apparent strain in compression increased after TM.

\section{Strain distribution around knots}

Levels of strain measured on unmodified and modified boards were similar and ranged between approx. 0 and $0.3 \%$ (Fig. 6). A clear shift in strain distribution after TM was observed for board $a$ (Fig. 6a). Elevated strain appeared at the tip of a check that ran from the board's edge a couple of $\mathrm{cm}$ into the board, whereas prior to modification elevated strain was also found at the board's edge. Strain distribution and level were similar prior to and after TM for board $g$, even though the investigated area contained considerable fibre deviation from the board's long axis (Fig. 6b). Measurements of strains exceeding $0.1 \%$, but below $0.5 \%$ may be caused by lower longitudinal elastic modulus of the wood and/or geometrical irregularities such as knots and/or deviation of fibres. It may therefore be important to note that $\varepsilon_{x}$ obtained with the ARAMISTM software and shown in Fig. 6, with respect to material direction, is a mix between longitudinal, transverse and shear strains since deviated fibres (e.g. around knots) are not loaded parallel to their axis. To illustrate this, when wood fibres are loaded under a 20 degree angle with respect to their length axis, the MOE can drop as much as $50 \%$ (Dinwoodie 2000), and hence at similar load levels higher strains would be measured in these areas. It is, however, likely that the shift in strain distribution after TM is related to a change in geometry, i.e. the reported build-up of checks around knots after thermal treatment, whereas the wood's (elastic) constants remain unaffected by TM as was shown previously (Majano-Majano et al. 2018). Effects appear very local, and the impact of increased checking after TM on a board's bending stiffness are limited as mentioned above (Table 1), which is consistent with previous results (Bengtsson et al. 2002; Widmann et al. 2012; van Blokland et al. 2020), but may have a direct influence on the development of failure in bending. 

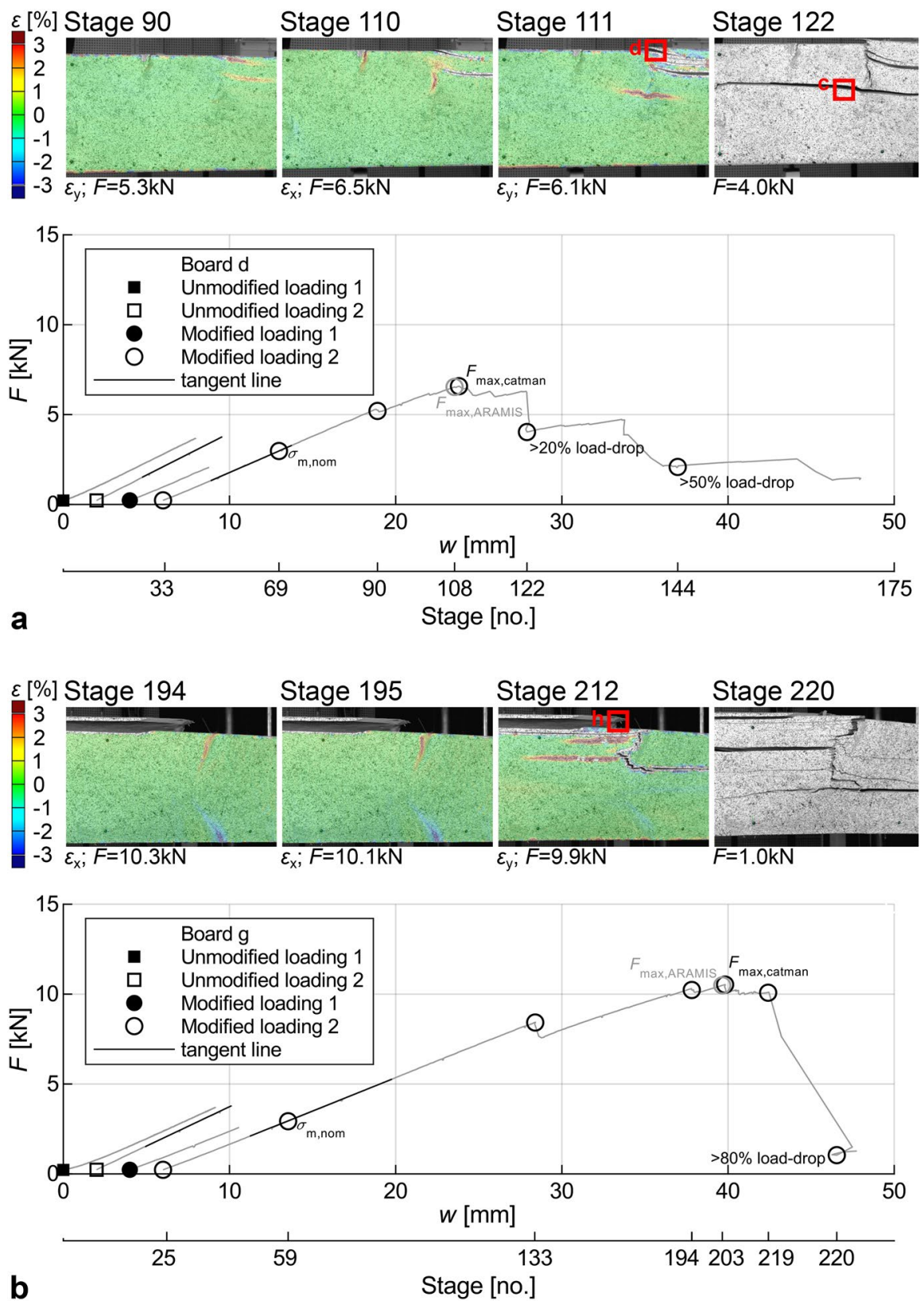

Fig. $7 F-w$ curves of both test runs for unmodified and modified a board $d$ and $\mathbf{b}$ board $g$, including stage number and strain fields at various stages. Note an offset of $2 \mathrm{~mm}$ was used on the $w$-axis between the different $F-w$ curves, the time scale of the stage-axis was adjusted to the deflection scale of the $w$-axis, and red boxes highlight samples taken for SEM 


\section{Failure in bending}

\section{Development of failure}

The load-deflection $(F-w)$ curves of bending tests and plots of axial $\left(\varepsilon_{x}\right)$ or transverse $\left(\varepsilon_{y}\right)$ strain at different key stages of modified boards $d$ and $g$ loaded to failure are shown in Fig. 7a, b, respectively. These two boards gave good representation for the 9 boards included in the study, and failure was clearly visible on the board side recorded by the cameras. A second $x$-axis in Fig. 7 shows the stage numbers, and an offset of $2 \mathrm{~mm}$ was used to plot the $F-w$ curves of previous non-destructive bending tests. The time scale of the stage-axis (stage/s) was chosen to fit the deflection scale of the $w$-axis in $\mathrm{mm}$. This time scale does not directly represent test duration, because the recording of strain stages was started prior to loading. In addition, there is a small difference between the $F-w$ curve from the DIC (not included in Fig. 7) and DAQ system, since data was recorded at a much higher frequency for the latter. This is clear with the location of $F_{\max }$ in Fig. 7. Finally, strain (\%) was plotted on a scale $[-3 ; 3]$ such that the development of failure upon loading could be monitored, i.e. yellow to red colours represent development of (surface) cracks. The results presented in Table 3 give an overview of the development of failure for all 9 TM boards and is based on similar analyses as in Fig. 7.

After loading modified board $d$ up to approx. $5 \mathrm{kN}$ (Fig. 7a, stage 90), longitudinal cracks developed besides intergrown knots (Fig. 2d, knot no. 4) and a splinter came loose on the tension edge. At this location, high shear strains around $0.3 \%$ had developed (data not included in Fig. 7a), and probably the longitudinal cracks in stage 90 were due to shear failure (see also Figs. 8d, 9d). This event corresponds to the jump in the $F-w$ curve. At the same time, wood at the knot interface on the backside of the board most likely failed in tension perpendicular to grain (see also Figs. 8d, 9f), but this cannot be observed on camera. Stage 110, which was taken $4 \mathrm{~s}$

after reaching $F_{\text {max }}$, shows that severe longitudinal cracks formed besides this knot, and a transverse crack developed in this intergrown knot. The board started to split and a lengthwise crack developed in the board centre (Fig. 7a, stage 111). When this crack had fully developed, the board lost more than $20 \%$ of its ultimate load-carrying capacity (Fig. 7a, stage 122). In board $g$ at stage 133, a splinter at the backside of the board came loose at an arris knot (Fig. 2g, knot no. 5), accompanied by a drop in the $F-w$ curve (Fig. $7 b$ ). Since the splay knot in the tensile zone was merely a fibre disturbance as the knot was sawn off, higher levels of strain started to develop only after loading the board up to about $10 \mathrm{kN}$. A sudden change in the strain pattern of $\varepsilon_{x}$ in the tensile zone between stage 194 and 195 indicated the formation of a crack above this 'superficial' splay knot, which ran towards the top of the board and was confirmed by the small jump in the $F-w$ curve (Fig. $7 b$ ). At $F_{\max }$, apparent $\varepsilon_{x}$ was mainly observed around this superficial splay knot, and failure at $F_{\max }$ was due to the formation of a transverse crack in this area with fibre deviation. Apparent transverse strain ran from this crack over the board illustrating the development of longitudinal cracking (Fig. 7b, stage 212). These cracks developed along the board and grew until stage 219 , when the board suddenly lost more than $80 \%$ of its maximum 


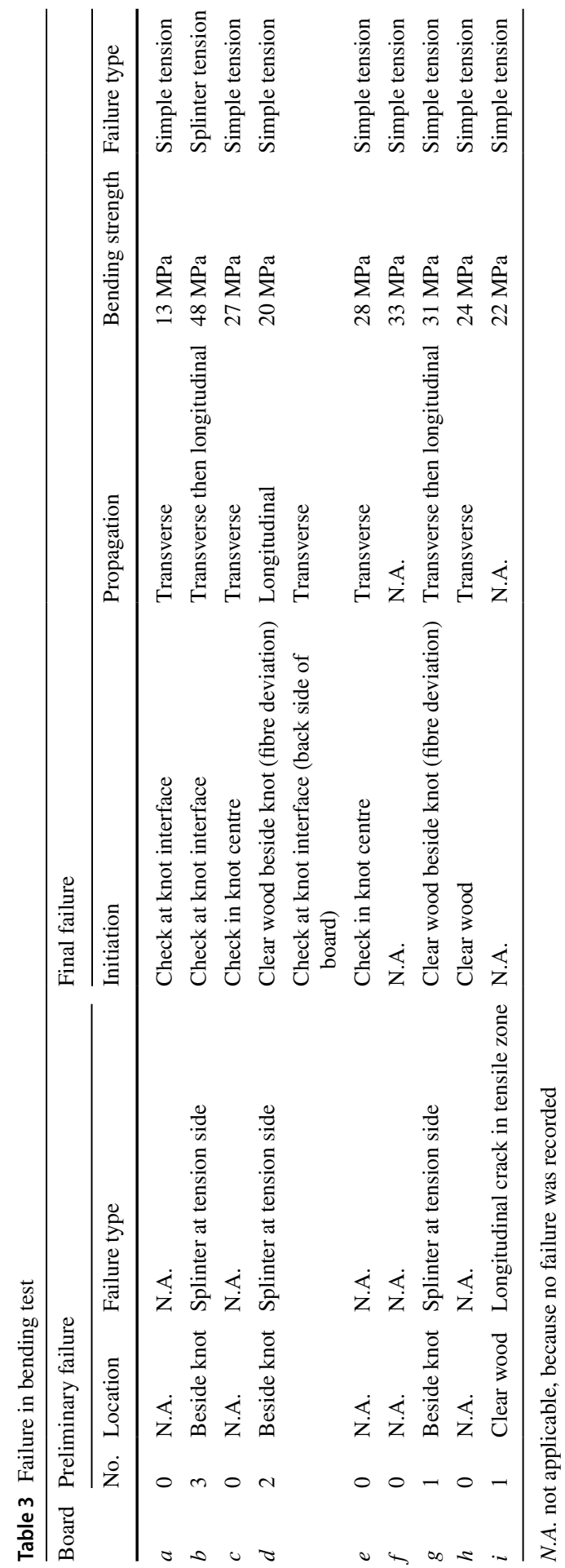



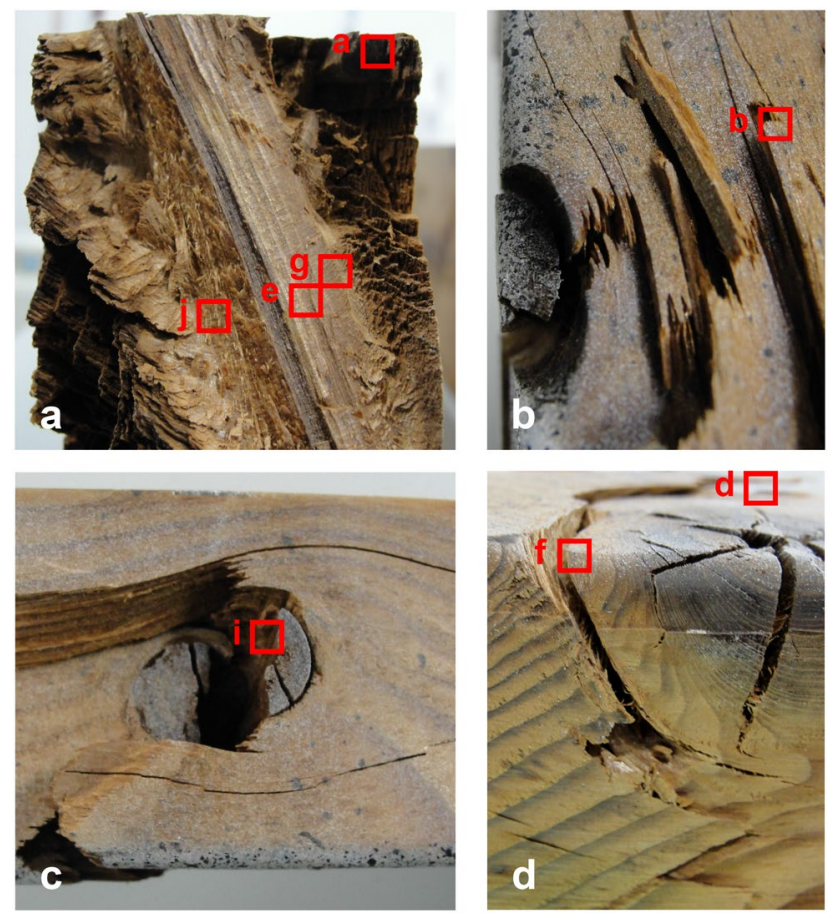

Fig. 8 Failures in the tensile zone of a transverse surface of board $a$ with intergrown edge knot, $\mathbf{b}$ top view of board $b$ with encased splay knot on left-hand side, $\mathbf{c}$ top view of board $c$ with encased edge knot, and $\mathbf{d}$ side view of board $d$ with intergrown splay knot. Note red boxes highlight samples taken for SEM

load-carrying capacity probably due to tensile failure perpendicular to grain similar to board $d$ (see also Fig. 9c).

Jumps in the $F-w$ curves were recorded for boards $b, d, g$ and $i$, and matched events of preliminary failure recorded on camera. For most cases, preliminary failures were related to some type of cross-grain tension failure where splinters were pulled loose on the tension side of the boards as discussed for the two examples (Table 3). In general, failure was initiated at checks in and around knots in the tensile zone. These checks propagate into larger cracks often running in transverse direction from the board's tensile edge into the board. After weakening of the top part, the boards split lengthwise along cracks originating from the transverse cracks, and high tensile strains develop perpendicular to the grain around the crack tip until final failure (e.g. see Fig. 7). This failure mechanism was clearly observed for all modified boards with the exception of board $f$ where the main failure occurred on the backside of the board, board $i$ where only clear wood was monitored, and board $h$ where failure occurred suddenly in a clear wood area where no extreme values of strains were recorded. The general failure mode therefore corresponds well to simple tension failure (ASTM D143-94 2000), which was the most common mode of failure for boards of unmodified and modified Norway spruce loaded in bending 

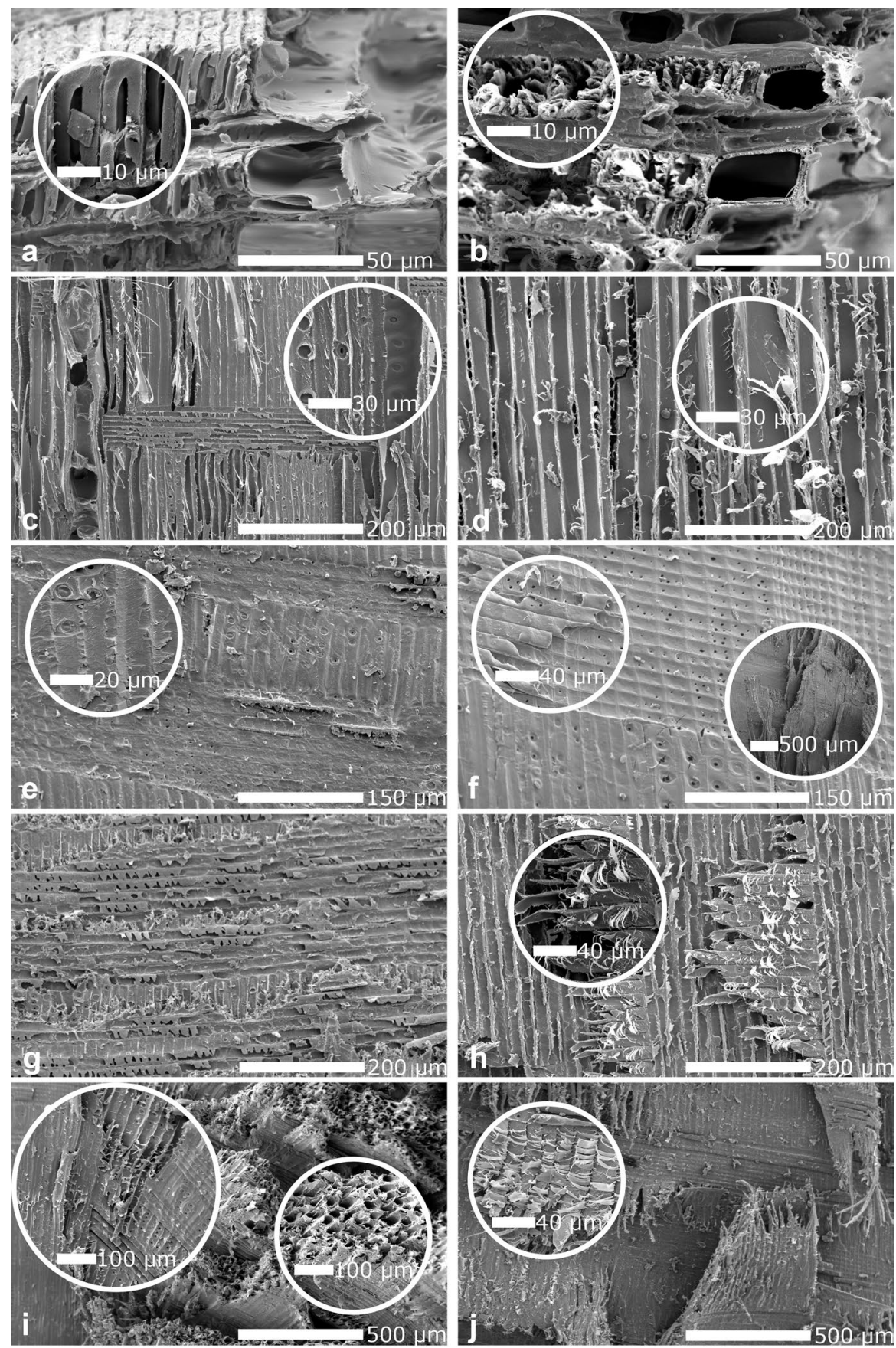

Fig. 9 SEM micrographs of the fracture surfaces of TMW: a clear wood-RT plane, b clear wood-RT plane, $\mathbf{c}$ clear wood-RL plane, $\mathbf{d}$ clear wood-TL plane, e knot wood-RL plane, $\mathbf{f}$ knot interface-RL plane, $\mathbf{g}$ knot interface-RL plane, $\mathbf{h}$ knot interface-RL plane, $\mathbf{i}$ knot-knot interface-RL and RT planes, and $\mathbf{j}$ knot interface-RL plane 
(van Blokland et al. 2020). Only board $b$ failed in splinter tension, a more ductile failure mode, and had a bending strength of almost $50 \mathrm{MPa}$.

\section{Macroscopic observations of fracture surfaces}

Examples of fracture surfaces in the tensile zone are shown in Fig. 8a-d for the transverse surface of board $a$, and for the edge of boards $b, c$ and $d$. For those boards where the development of failure was recorded (i.e. boards $a, b, c, d, e$ and $g$ ), failure was initiated at sites of knots (Table 3) with exception of board $h$. This is consistent with van Blokland et al. (2020), but contrasts with Boonstra et al. (2007) who found no clear effect of defects like knots on bending strength and stiffness of TMT. Most failures were initiated at knot interfaces or besides knots. The final failure of board $a$ in Fig. 8a, however, suggested that failure was through the knot centre. This exemplifies earlier work (van Blokland et al. 2020), which concluded that failure in TMT occurs more often through rather than around knots like unmodified timber. An observation that may be biased, since only final failure was evaluated in that study. Severe checking of knots in TMT of Norway spruce would have contributed to knots falling apart after final failure in bending, whereas the actual failure may have been in wood located around the knot as was shown here. Failure occurred once through an encased edge knot for board $c$ (Fig. 8c); and once through an intergrown splay knot for board $e$. Presumably, failure was initiated around the knots as well, since the knots were already fully cracked before loading, but this could not be observed when observing measures of surface strain.

Previous studies showed that TMW is more prone to initiation and propagation of factures, since both fracture toughness $\left(K_{\mathrm{Ic}}\right)$ along the grain of spruce wood and fracture energy $\left(G_{\mathrm{f}}\right)$ decreased as much as $50 \%$ due to TM (Reiterer and Sinn 2002; Murata et al. 2013; Pleschberger et al. 2014; Tukiainen and Hughes 2016). It was therefore expected that increased checking around knots may contribute to the loss in bending strength found after TM. Current results, however, are inadequate to determine whether increased checking contributes to this loss in strength. Resistance to fracture (i.e. up to the point of crack initiation and propagation) should be similar between unmodified and modified wood, since stiffness measured in fracture mechanical tests up to the point of crack initiation $\left(k_{\text {init }}\right)$ were not influenced or even increased after TM (Reiterer and Sinn 2002; Majano-Majano et al. 2012; Tukiainen and Hughes 2016). This is consistent with results showing that increased checking at sites of knots has no significant influence on the (local) bending stiffness of TMT. Values of $\mathrm{K}_{\mathrm{Ic}}$ for softwoods are typically 10 times larger across than along the grain (Ashby et al. 1985). This ratio has not been established for TMW (Reiterer and Sinn 2002; Majano-Majano et al. 2010, 2012; Murata et al. 2013; Pleschberger et al. 2014; Tukiainen and Hughes 2016). Based on the assessment of work-to-maximum load of TM clear wood, it can be expected that $K_{\text {Ic }}$ across the grain is also reduced up to $50 \%$ or more by TM (MacLean 1954; Kubojima et al. 2000). Further studies regarding this ratio may be used to determine whether the loss in timber bending strength after TM is governed by straight-grained (clear wood) or deviated fibres (i.e. around knots). 


\section{SEM analyses}

Details of fracture surfaces of SEM samples a-j, highlighted in Figs. 7 and 8, are shown at higher magnifications in Fig. 9. Clear wood samples fractured across the grain are displayed in Fig. 9a, b, and those fractured along the grain in the longitudinal-radial plane (i.e. TL fracture) in Fig. 9c and in the longitudinal-tangential plane (i.e. RL fracture) in Fig. 9d. In wood of knots and at knot interfaces, primarily TL fractures were observed, as shown in Fig. 9e-j.

Tensile failure in clear wood specimens that were sampled close to the board's top edge developed mainly across the grain producing transwall failure in earlywood (EW) and latewood (LW) tracheids, and rays (Fig. 9a, b). The transwall fractures in boards $a$ (Fig. 9a) and $h$ (not shown) were smooth over the whole area and particularly evident in the secondary cell wall (S2) layers of EW and LW tracheids and ray parenchyma (Fig. 9a detail). This observation agrees with earlier investigations showing transwall failure in unmodified wood and in TMW after tensile failure across the grain (Boonstra et al. 2006a, b; Arnold 2010). Possible reasons for the loss in strength after TM include degradation and loss of hemicelluloses, the increase in crystalline cellulose and modification of lignin (Boonstra et al. 2007; Windeisen et al. 2009). It is likely that some of these changes in chemistry are also responsible for the smooth appearance of transwall failures. Transwall fractures in EW and LW cells of board $b$ appeared more serrated and followed the orientation of cellulose microfibrils, particularly in the S2 layer of thick-walled LW tracheids (Fig. 9b detail). Thus, transwall fracture in this board showed some similarity to fractures observed in unmodified wood (Côté and Hanna 1983; Boonstra et al. 2006a, b; Arnold 2010). The so-called 'unwinding of the S2 layer' would have been caused by slippage between microfibrils (Côté and Hanna 1983). In addition, some intrawall failure was observed in the sample taken from board $b$ (Fig. 9b), which was not visible in the sample taken from board $a$ (Fig. 9a). The less and more brittle behaviour of boards $a$ and $b$ respectively seen at the ultrastructural level is consistent with the less brittle failure mode of board $b$ and a more brittle failure mode of board $a$ observed at the macroscopic level (Fig. 8a, b). The bending failure of clear wood in board $h$ (Table 3) was explained by the presence of compression wood confirmed by SEM (not shown). TL fractures in clear wood appeared transwall in thin-walled EW tracheids and ray cells, whereas this fracture developed intrawall in LW tracheids. The fracture plane had evolved from ray to ray. The intrawall failure followed the radial cell wall of the S2 layer or the S2-S3 interface (Fig. 9c detail of EW-LW boundary). These observations correspond to previous SEM studies on TL fracture of unmodified wood loaded in mode I or II (Côté and Hanna 1983; Majano-Majano et al. 2012). RL fractures developed mainly transwall. This was through the radial wall of EW tracheids with the rays cut cleanly (Fig. 9d). The fracture surface was dominated by a stringy appearance, which was caused by the additional intrawall failure at the S1-S2 interface such that S2 and S3 fibre walls were 'pulled out' (Fig. 9d bottom right and detail). This phenomenon was reported earlier for RL fractures under mode II loading (i.e. tangential shear) of unmodified southern pine (Côté and Hanna 1983). This is consistent with the shear forces measured in this region 
on the surface of board $d$ ("Development of failure" section). Reiterer and Sinn (2002) observed only transwall failure after RL fracture of thermally modified spruce in contrast to transwall and intrawall failure of unmodified spruce. This difference was probably caused by the fact that in that work fracture was under pure mode I, whereas the RL fracture shown in Fig. 9d resulted from mixed mode I and II loading (Côté and Hanna 1983; Jernkvist 2001). The TL crack along the rays and across EW tracheids, observed in the top centre of Fig. 9d, was not typical but taken adjacent to the transverse fracture surface at the top of the sample.

Fractures in and around knots mainly developed in the TL system as seen in Fig. 9e-j. This is related to the presence of wood rays (Frühmann et al. 2003), which provide reinforcement upon RL failure and planes of weakness upon TL failure. Values for fracture energy are therefore lower for TL than RL fractures, both for hardwoods and softwoods that are unmodified or thermally modified (Ashby et al. 1985; Majano-Majano et al. 2010, 2012; Murata et al. 2013). Fractures around knots (Fig. 9i right) and at knot interfaces (Fig. 9g, h, j) were also across tracheids. Both fracture types developed along the rays and were rather similar to TL fractures observed in clear wood (Fig. 9c). Within knots (Fig. 9e, i left) and at knot interfaces (Fig. 9f), fracture surfaces were extremely smooth and failure lines were intercellular between tracheids (probably at the compound middle lamella and S1 layer) and ray cells. This contrasts with the intrawall fractures through EW and ray cells seen in clear wood, and more like cell wall delamination seen for areas with LW in clear wood (Fig. 9c). It is known that cracks in wood typically advance transwall for mean density-cell wall density $\left(\rho / \rho_{\mathrm{s}}\right)$ ratios below 0.2, and intercell or intrawall for ratios above 0.2 (Ashby et al. 1985). The spruce wood used in the present study had a $\rho / \rho_{\mathrm{s}}$ ratio of 0.3 based on average board density. The $\rho / \rho_{\mathrm{s}}$-ratio of EW was most likely below 0.2 and knot wood can be expected to be as much as 0.5-0.7 (Boutelje 1966; Frühmann et al. 2003). This is highlighted in Fig. 9i (detail left), where EW cells at the knot's interface with large lumens and thin cell walls failed transwall like the TL fractures of EW in clear wood. The surrounding cells however remained rather intact and failure was intercellular. Figure $9 \mathrm{~g}$ shows the fracture surface at the knot interface and came from the same region as Fig. 9e but slightly closer to the outer border of the knot. Fracture was here through the rays and across tracheids (transwall) as well as between fibres (intercell or intrawall). Figure $9 \mathrm{~h}$ shows a somewhat similar fracture surface; however, this time the fibres had fractured intracellular at the S1-S2 interface and the transwall failure followed the microfibrillar angle in the S2 layer. Figure 9i shows an example of fracture with a more abrupt transition between knot and clear wood. The clear wood seen on the right-hand side of Fig. 9i, failed mainly across the grain, but shows more unwinding of the S2 layer compared to the earlier discussed cross-grain fractures in clear wood. Figure $9 \mathrm{j}$ shows the fracture plane from the same knot as in samples e and $g$, but here the surface appeared smoother than suggested by the naked eye (Fig. 8a). The appearance was quite similar to Fig. 9h under the SEM, and shear forces must have been present, since some rows with fibres were pulled out.

From the SEM results, it seems that in clear wood or knot wood, fractures develop under mode I loading across or along the fibres (Fig. 9a-c, e), because smooth 
fracture surfaces were evident (Jernkvist 2001). In areas around knots and at knot interfaces (i.e. with fibre deviation) fractures developed under mixed mode I and II loading mostly along the fibres (Fig. 9d, f-j), since fracture growth required transverse cutting of tracheid walls (Jernkvist 2001). Overall, at cellular level, fractures in TMW develop quite similar to unmodified wood. However, at the ultrastructural level differences become clear i.e. extreme smooth transwall fractures. The reason for this is most likely caused by changes in wood chemistry after thermal modification as was discussed earlier (Boonstra et al. 2007; Windeisen et al. 2009).

\section{Conclusion}

Nine boards of Norway spruce were used to study the combined effect of checks and knots on the bending strength and stiffness of thermally modified timber (TMT). The number and size of (surface) checks in knots increased after thermal modification (TM) compared to kiln-dried timber, especially for intergrown knots and intergrown parts of encased knots. This was confirmed by locations of both apparent and actual strains around knots obtained by DIC on boards subjected to bending before and after TM. Effects appear local, i.e. shifts in strain distribution at sites of knots after TM were related to the build-up of checks, but did not affect the board's bending stiffness at these sites. Bending failure in TMT initiated mainly at knot interfaces or beside knots and fractures often propagated from checks, but it was not possible to determine whether the increased checking contributes to the loss in bending strength found after TM. On the macroscopic scale, the general failure mode remained similar after TM, i.e. simple tension failure. It was concluded from the SEM analyses, that this type of failure was primarily initiated by TL fracture that developed around knots and at knot interfaces under mixed mode I and II loading. At the cellular level, fracture in TMT develops quite similar to unmodified wood. However, the more brittle behaviour of thermally modified wood becomes clear at the ultrastructural level, specifically with transwall failure that appears smooth under mode I loading across the grain. For better understanding of the bending strength and stiffness behaviour of TMT of Norway spruce, it would be interesting to complement existing fracture mechanical investigations on thermally modified wood with tests across the grain under mode I loading and along the grain under mode II loading, in particular in the TL crack propagation system.

Acknowledgements Open access funding provided by Linnaeus University. This research received funding provided by the Formas project "New aspects on the strength behaviour of thermally modified wood towards structural applications" (Grant No. 942-2015-722, coordinator Prof. S. Adamopoulos). The timber and thermal modification were provided by Stora Enso Timber AB, Sweden.

\section{Compliance with ethical standards}

Conflict of interest On behalf of all authors, the corresponding author states that there is no conflict of interest. 
Open Access This article is licensed under a Creative Commons Attribution 4.0 International License, which permits use, sharing, adaptation, distribution and reproduction in any medium or format, as long as you give appropriate credit to the original author(s) and the source, provide a link to the Creative Commons licence, and indicate if changes were made. The images or other third party material in this article are included in the article's Creative Commons licence, unless indicated otherwise in a credit line to the material. If material is not included in the article's Creative Commons licence and your intended use is not permitted by statutory regulation or exceeds the permitted use, you will need to obtain permission directly from the copyright holder. To view a copy of this licence, visit http://creativecommons.org/licen ses/by/4.0/.

\section{References}

Altgen M, Adamopoulos S, Ala-Viikari J, Hukka A, Tetri T, Militz H (2012) Factors influencing the crack formation in thermally modified wood. In: Proceedings of the 6th European conference on wood modification, Ljubljana, Slovenia, pp 149-158

Altgen M, Adamopoulos S, Militz H (2017) Wood defects during industrial-scale production of thermally modified Norway spruce and Scots pine. Wood Mater Sci Eng 12(1):14-23

Arnold M (2010) Effect of moisture on the bending properties of thermally modified beech and spruce. J Mater Sci 45:669-680

Ashby MF, Easterling KE, Harrysson R, Maiti SK (1985) The fracture and toughness of woods. Proc R Soc Lond A 398:201-280

ASTM D143-94 (2000) Standard test methods for small clear specimens of timber. ASTM International, West Conshohocken

Bengtsson C, Jermer J, Brem F (2002) Bending strength of heat-treated spruce and pine timber. In: Proceedings of the international research group on wood preservation, Document No. IRG/WP 02-40242, Cardiff, Wales

Bernabei M, Salvatici MC (2016) In situ ESEM observations of spruce wood (Picea abies Karst.) during heat treatment. Wood Sci Technol 50(4):715-726

Biziks V, Andersons B, Beḷkova L, Kapač E, Militz H (2013) Changes in the microstructure of birch wood after hydrothermal treatment. Wood Sci Technol 47:717-735

Boonstra MJ, Rijsdijk JF, Sander C, Kegel E, Tjeerdsma B, Militz H, van Acker J, Stevens M (2006a) Microstructural and physical aspects of heat treated wood-part 1: softwoods. Maderas Cienc Technol 8(3):193-208

Boonstra MJ, Rijsdijk JF, Sander C, Kegel E, Tjeerdsma B, Militz H, van Acker J, Stevens M (2006b) Microstructural and physical aspects of heat treated wood-part 2: hardwoods. Maderas Cienc Technol 8(3):209-217

Boonstra MJ, Van Acker J, Tjeerdsma BF, Kegel EV (2007) Strength properties of thermally modified softwoods and its relation to polymeric structural wood constituents. Ann For Sci 64(7):679-690

Boutelje JB (1966) On the anatomical structure, moisture content, density, shrinkage, and resin content of the wood in and around knots in Swedish pine (Pinus silvestris L.) and in Swedish spruce (Picea abies Karst.). Svensk Paperstidning 69(1):1-10

Candelier K, Thevenon M-F, Petrissans A, Dumarcay S, Gerardin P, Petrissans M (2016) Control of wood thermal treatment and its effects on decay resistance: a review. Ann For Sci 73(3):571-583

Côté WA, Hanna RB (1983) Ultrastructural characteristics of wood fracture surfaces. Wood Fiber Sci $15(2): 135-163$

Dinwoodie JM (2000) Timber: its nature and behaviour. Taylor and Francis, Abingdon

EN 1912 (2012) Structural Timber-strength classes-assignment of visual grades and species. European Committee for Standardization (CEN), Brussels

EN 408 (2012) Structural timber-structural timber and glued laminated timber-determination of some physical and mechanical properties. European Committee for Standardization (CEN), Brussels

EN 13183-1 (2002) Moisture content of a piece of sawn timber-part 1: determination by oven dry method. European Committee for Standardization (CEN), Brussels

EN 14081-1 (2016) Timber structures-strength graded structural timber with rectangular cross section-part 1: general. European Committee for Standardization (CEN), Brussels 
Florisson S, Ormarsson S, Vessby J (2019) A numerical study of the effect of green-state moisture content on stress development in timber boards during drying. Wood Fiber Sci 51(1):41-57

Folvik K, Sandland KM (2003) Occurrence of checks in knots of Norway spruce timber during drying. The effect of various drying schedules. In: Proceedings of the 8th IUFRO international wood drying conference, Brasov, Romania

Folvik K, Sandland KM (2005) Various wood properties influencing the development of checks in knots during drying. Rep. 58, Norsk Treteknisk Institutt, pp 67-74

Frühmann K, Burgert I, Stanzl-Tschegg SE, Tschegg EK (2003) Mode I fracture behaviour on the growth ring scale and cellular level of spruce (Picea abies [L.] Karst.) and beech (Fagus sylvatica L.) loaded in the TR crack propagation system. Holzforsch 57:653-660

Gaff M, Kačík F, Sandberg D, Babiak M, Turčani M, Niemz P, Hanzlík P (2019) The effect of chemical changes during thermal modification of European oak and Norway spruce on elasticity properties. Compos Struct 220:529-538

Hanhijärvi A, Ranta-Maunus A (2008) Development of strength grading of timber using combined measurement techniques. Report of the Combigrade-project-phase 2. VTT Publications 686

Hannouz S, Collet R, Butaud J-C, Bleron L, Candelier K (2015) Mechanical characterization of heattreated ash wood in relation with structural timber standards. Pro Ligno 11:3-10

$\mathrm{Hu}$ M, Johansson M, Olsson A, Oscarsson J, Enquist B (2015) Local variation of modulus of elasticity in timber determined on the basis of non-contact deformation measurement and scanned fibre orientation. Eur J Wood Prod 73:17-27

Hu M, Olsson A, Johansson M, Oscarsson J, Serrano E (2016) Assessment of a three-dimensional fiber orientation model for timber. Wood Fiber Sci 48(4):1-20

Hu M, Briggert A, Olsson A, Johansson M, Oscarsson J, Säll H (2018) Growth layer and fibre orientation around knots in Norway spruce: a laboratory investigation. Wood Sci Technol 52(1):7-27

Hughes M, Hill CAS, Pfriem A (2015) The toughness of hygrothermally modified wood-a review. Holzforsch 69(7):851-862

INSTA 142 (2010) Nordic visual strength grading rules for timber (in Swedish). Swedish Standards Institute (SIS), Stockholm

International ThermoWood Association (2003) ThermoWood handbook. International ThermoWood Association, Helsinki

Jernkvist LO (2001) Fracture of wood under mixed mode loading I. Derivation of fracture criteria. Eng Fract Mech 68:549-563

Johansson C-J (2003) Grading of timber with respect to mechanical properties. In: Thelandersson S, Larsen HJ (eds) Timber engineering. Wiley, West Sussex

Kollmann FFP (1968) Mechanics and rheology of wood. In: Kollmann FFP, Côté WA Jr (eds) Principles of wood science and technology: I solid wood. Springer, New York

Kubojima Y, Okano T, Ohta M (2000) Bending strength and toughness of heat-treated wood. J Wood Sci 46:8-15

Lukacevic M, Kandler G, Hu M, Olsson A, Füssl J (2019) A 3D model for knots and related fiber deviations in sawn timber for prediction of mechanical properties of boards. Mater Des. https://doi. org/10.1016/j.matdes.2019.107617

MacLean JD (1954) Effect of heat on the properties and serviceability of wood: experiments on thin wood specimens. Technical report, U.S. Department of Agriculture, Forest Service, Forest Products Laboratory, Madion 5, Wisconsin

Majano-Majano MA, Hughes M, Fernández-Cabo JL (2010) A fracture mechanics study of thermally modified beech for structural applications. In: Proceedings of the World conference on timber engineering, Riva del Garda, Italy

Majano-Majano MA, Hughes M, Fernandez-Cabo JL (2012) The fracture toughness and properties of thermally modified beech and ash at different moisture contents. Wood Sci Technol 46:5-21

Majano-Majano MA, Gómez-Royuela JL, Lara-Bocanegra AJ (2018) Elastic constants of thermally treated beech by ultrasound tests. In: Proceedings of the World conference on timber engineering, Seoul, Republic of Korea

Mergny E, Mateo R, Esteban M, Descamps T, Latteur P (2016) Influence of cracks on the stiffness of timber structural elements. In: Proceedings of the World conference on timber engineering, Vienna, Austria

Metsä-Kortelainen S, Paajanen L, Viitanen H (2011) Durability of thermally modified Norway spruce and Scots pine in above-ground conditions. Wood Mater Sci Eng 6:163-169 
Murata K, Watanabe Y, Nakano T (2013) Effect of thermal treatment on fracture properties and adsorption properties of spruce wood. Materials 6:4186-4197

Olsson A, Oscarsson J (2017) Strength grading on the basis of high resolution laser scanning and dynamic excitation: a full scale investigation of performance. Eur J Wood Prod 75(1):17-31

Olsson A, Oscarsson J, Serrano E, Källsner B, Johansson M, Enquist B (2013) Prediction of timber bending strength and in-member cross-sectional stiffness variation on the basis of local wood fibre orientation. Eur J Wood Prod 71:319-333

Oscarsson J, Olsson A, Enquist B (2012) Strain fields around knots in Norway spruce specimens exposed to tensile forces. Wood Sci Technol 46:593-610

Paulínyová JM, Čunderlík I (2006) Chosen physical properties of spruce juvenile wood (Picea abies Karst.). In: Proceedings of the 5th IUFRO symposium “wood structure and properties '06”, SliačSielnica, Slovakia, pp 93-97

Perstorper M (1994) Quality of structural timber-end-user requirements and performance control. PhD thesis, Chalmars tekniska högskola, Gothenburg, Sweden

Pleschberger H, Teischinger A, Müller U, Hansmann C (2014) Change in fracturing and colouring of solid spruce and ash wood after thermal modification. Wood Mater Sci 9(2):92-101

Reiterer A, Sinn G (2002) Fracture behaviour of modified spruce wood: a study using linear and non linear fracture mechanics. Holzforsch 56:191-198

Rowell RM, Ibach RE, McSweeny J, Nilsson T (2009) Understanding decay resistance, dimensional stability and strength changes in heat treated and acetylated wood. In: Proceedings of the 4th European conference on wood modification, Stockholm, Sweden, pp 489-502

Rowell RM, Andersone I, Andersons B (2013) Heat treatment. In: Rowell RM (ed) Handbook of wood chemistry and wood composites. CRC Press LLC, Boca Raton, pp 511-536

Saranpää P (2008) Basic density, longitudinal shrinkage and tracheid length of juvenile wood of Picea abies (L.) Karst. Scand J For Res 9(1-4):68-74

Sjödin J, Serrano E, Enquist B (2006) Contact-free measurements and numerical analyses of the strain distribution in the joint area of steel-to-timber dowel joints. Holz Roh Werkst 64:497-506

Tsoumis GT (1991) Science and technology of wood: structure, properties, utilization. Van Nostrand Reinhold, New York

Tukiainen P, Hughes M (2016) The effect of elevated temperature and high moisture content on the fracture behaviour of thermally modified spruce. J Mater Sci 51:1437-1444

van Blokland J, Olsson A, Oscarsson J, Adamopoulos A (2020) Prediction of bending strength of thermally modified timber using high-resolution scanning of fibre direction. Eur J Wood Prod 77(3):327-340. https://doi.org/10.1007/s00107-019-01388-w

van der Beek J, Tiitta M (2010) Monitoring the Thermowood process by means of acoustic emission technology. In: Proceedings of the 29th European conference on acoustic emission testing, Vienna, Austria

Widmann R, Fernandez-Cabo JL, Steiger R (2012) Mechanical properties of thermally modified beech timber for structural purposes. Eur J Wood Prod 70:775-784

Winandy JE, Rowell RM (2013) Chemistry of wood strength. In: Rowell RM (ed) Handbook of wood chemistry and wood composites. CRC Press LLC, Boca Raton, pp 413-455

Windeisen E, Bächle H, Zimmer B, Wegener B (2009) Relations between chemical changes and mechanical properties of thermally treated wood. Holzforsch 63:773-778

Publisher's Note Springer Nature remains neutral with regard to jurisdictional claims in published maps and institutional affiliations. 